Article

\title{
Use of Phentolamine Mesylate in implant surgery. Analysis of adverse effects and haemodynamic changes
}

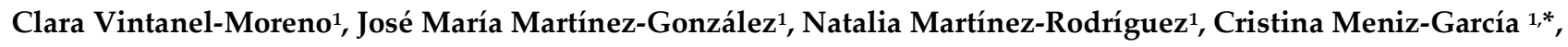 \\ Isabel Leco-Berrocal ${ }^{1}$ \\ 1 Department of Dental Clinical Specialties, Faculty of Dentistry, Complutense University of Madrid, Spain; \\ clara.vintanel@gmail.com (C.V.M.); jmargo@ucm.es (J.M.M.G.); hospinatmr@hotmail.com (N.M.R.); \\ cmenizga@ucm.es (C.M.G.); mileco@ucm.es (I.L.B.) \\ * Correspondence: cmenizga@ucm.es (C.M.G.); Tel.: +34 609016107
}

\begin{abstract}
The clinical application of Phentolamine Mesylate (PM) as an anaesthetic reversal agent has been documented in paediatric patients and in conservative dentistry, but no studies have been found in implant surgery. A prospective randomised study was conducted in 60 patients eligible for mandibular implant treatment, randomly divided between the Control Group (CG) and Experimental Group (EG), who were administered PM. Haemodynamic changes, adverse effects and patient satisfaction were assessed. No statistically significant differences in haemodynamic changes and postoperative pain were found between CG and EG $(p<0.05)$, except for Systolic Blood Pressure (SBP) which increased slightly in EG, without posing a risk to the patient. There were no differences in the presence of adverse effects between the two groups, except in the CG which presented greater difficulty in chewing and biting $(p<0.05)$ and the EG with greater pain in the injection area ( $p=0.043$ ). $83.3 \%$ of the EG patients would request PM again for future dental treatment. The use of PM offers an alternative in implant surgery, without increasing the risks and increasing the patient's quality of life.
\end{abstract}

Keywords: Phentolamine Mesylate; dental implants; haemodynamic changes; adverse effects; satisfaction

\section{Introduction}

Local anaesthetics used in the oral cavity often last much longer than the working time, which can lead to a decrease in the quality of life of patients who undergo dental treatment.

All anaesthetic techniques used produce a total or partial loss of soft tissue sensitivity of between 3 and 5 hours [1-4], which is often longer than the working time and the time needed for pain control after restorative and periodontal procedures [5,6]. This duration is most often associated with difficulty in eating, drinking, speaking and smiling [7-11], and can cause biting injuries to the lips, tongue and cheeks, especially in children and disabled people $[12,13]$. Some patients consider it to be a temporary decrease in their quality of life $[7,12,14]$, affecting their normal daily activity in three areas: perceptual (altered perception of physical appearance), sensory (lack of sensation) and functional (impaired ability to speak, smile, drink and control salivation) [5,14-16].

The use of an anaesthetic reversal agent such as PM is documented in the literature. In dentistry, it is used to eliminate the anaesthetic in the area where it is injected, due to the vasodilatation that occurs, considering that its mechanism of action is due to an increase in blood flow [17]. PM is not an anaesthetic antagonist, but an antagonist of the vasoconstrictor with which the anaesthetic is associated, so it should not be used to reverse anaesthetics that are not associated with a vasoconstrictor [18].

PM is a non-specific $\alpha$-adrenergic inhibitor whose effect is vasodilation of the vascular system $[7,8,11,17]$. It acts by inhibiting the ability of sympathomimetic amines, 
such as norepinephrine and epinephrine, to stimulate vascular contraction [19,20]. Because it is an $\alpha$-adrenergic inhibitor, special attention should be paid to any cardiovascular changes that may occur, such as hypotension and/or tachycardia after injection [9]. Due to the vasodilatation that occurs in the area following its injection, its mechanism of action is believed to be an increase in blood flow, eliminating the anaesthetic from the area [17].

Its clinical application is documented in paediatric patients, as reflected in the study by Tavares et al. [21], which shows a decrease in the duration of the anaesthetic effect after restorative and hygienic treatments; the main adverse effects are pain at the injection site, minor alterations in vital signs and post-treatment pain. Along the same lines, Nourbakhsh et al. [5] analysed the effect of PM in routine dental treatments in children aged 4 to 11 years, anaesthetised with lidocaine $2 \%$ associated with epinephrine 1:80,000, finding statistically significant differences in the duration of the anaesthetic effect between the group in which PM was used and the placebo group. The adverse effects found were one patient who experienced nausea and one patient who experienced a rise in temperature after PM injection.

In adult patients, Fowler et al. [15] analysed the usefulness of PM in maxillary or mandibular endodontic treatment of asymptomatic teeth, using lidocaine $2 \%$ in association with epinephrine 1:100,000 in all cases. Differences in the duration of the anesthetic effect were confirmed and the main adverse effect was subjective intraoral swelling in the group in which PM had been injected.

There are many studies that use PM in different dental procedures, but not in implantology, so this study was developed to address the current demand for these treatments. The objectives were to analyse the haemodynamic changes and the occurrence of adverse effects attributable to PM, as well as the recommendation of its use in adult patients undergoing implant treatment.

\section{Materials and Methods}

\subsection{Study design and patient selection}

A prospective, longitudinal study was designed at the Faculty of Dentistry of the Complutense University of Madrid, based on approval by the Ethics Committee of the Hospital Clínico San Carlos (18/011-O_EPASP), and following the recommendations of the Declaration of Helsinki.

The study included patients who requested implant treatment and required the placement of two mandibular implants in premolar and molar position, and who met the inclusion criteria: patients over 18 years of age; belonging to the ASA 1 group; voluntary participation in the study; anaesthetic latency time of less than 4 minutes; and diagnostic CBCT prior to implant placement (iCAT Vision. Next Generation. Imagin Sciences International, Inc. Hatfield, PA, USA).

This three-dimensional study assessed whether the bone availability was sufficient for the placement of a dental implant, maintaining between 1.5-2 $\mathrm{mm}$ of bone in the vestibular area and between 1-1.5 $\mathrm{mm}$ of bone in the lingual area. If this was not the case, these patients were excluded from the study because bone regeneration was required, either prior to implant placement or simultaneously with implant placement. Patients whose questionnaire was incomplete, ASA II, III, IV patients, patients for whom more than two carpules of anaesthetic were necessary for treatment, patients with arterial hypertension (AHT) or alterations in heart rate (HR), patients chronically taking antiinflammatory and/or analgesic drugs, patients taking any other type of medication, and those who did not wish to participate in the study were excluded.

Inclusion was by probability sampling of consecutive cases, with all patients who met the inclusion criteria and who voluntarily agreed to participate in the study. For this purpose, they were given an information sheet and the purpose of the procedure was explained verbally, as well as the possible adverse effects, and they signed an informed consent form prior to the procedure. 
A total of 60 patients were included, which were randomly distributed, 30 in the Control Group (CG) and 30 in the Study Group (EG).

All patients were fitted with two Biohorizons ${ }^{\circledR}$ brand dental implants (Tapered Internal with Laser Lock. Birmingham, AL, USA) of the most suitable diameter and length according to the bone availability shown on the $\mathrm{CBCT}$.

\subsection{Surgical technique}

Implant placement was always performed by the same surgeon and following the same surgical protocol. An inferior alveolar and lingual nerve block was performed, followed by buccal nerve reinforcement using a $1.7 \mathrm{ml}$ carpule of $4 \%$ Articaine and Adrenaline 1:100000 (Septanest ${ }^{\circledR}$ 1/100000. Septodont. France) in each of the injections. Subsequently, all patients were rinsed with chlorhexidine digluconate (Lacer ${ }^{\circledR}$ chlorhexidine. Barcelona, Spain) $0.20 \%$ for 60 seconds.

A crestal incision was made and a full-thickness mucoperiosteal flap was raised, drilling was performed with abundant flushing to avoid bone necrosis, and the implants were mechanically placed. The incision area was sutured with $4 / 0$ silk using simple stitches (Supramid ${ }^{\circledR}$ Aragó ${ }^{\circledast}$. Spain). Once the procedure was finished, a $1.7 \mathrm{ml}$ carpule of PM (OraVerse ${ }^{\circledR}$. Septodont. France) was injected.

A data collection form was used to record the time of the start of the procedure, prior to the injection of the anaesthetic solution, the time at which the patient began to feel lip numbness (latency period, from the start of the injection of the anaesthetic solution until the patient felt lip numbness), and the end of the procedure, after the suturing was completed.

\subsection{Data recording and monitoring}

All patients were monitored by measuring systolic blood pressure (SBP) and diastolic blood pressure (DBP) using a blood pressure monitor (Omron M3 Comfort ${ }^{\circledR}$ HEM-7155E. Spain), and $\mathrm{HR}$ and $\mathrm{O}_{2}$ saturation $\left(\mathrm{SaO}_{2}\right)$ using a Bippex pro Apex Medical ${ }^{\circledR}$ (Iberomed. Spain) handheld digital pulse oximeter. In both groups, recordings were made prior to the injection of the anaesthetic solution to obtain the baseline measurement, and 10 minutes after the end of the procedure in the CG and 10 minutes after injection of PM in the EG. Patients were reviewed at 24, 48 and 96 hours for adverse effects and at 7 days for suture removal.

Patients were given a sheet with the instructions to be followed in the days following the procedure, and all were prescribed amoxicillin $750 \mathrm{mg} \mathrm{1/8} \mathrm{hours} \mathrm{for} 7$ days and paracetamol $650 \mathrm{mg}$ as analgesic treatment, if necessary.

All patients were given a questionnaire in which they were asked to record the intensity of pain using a visual analogue scale (VAS) (0-10) and the number of analgesics taken at 6,12 and 24 hours after the end of the procedure, as well as in the following days. And a second 11-item questionnaire, which included clinical aspects on the consequences of the anaesthetic effects and possible adverse effects, to be completed and returned 24 hours after the procedure, assessing, among other aspects, whether they had experienced speech disorders, strange sensations, palpitations or dizziness, or any neck or head pain, etc. The records were made using a Likert-type scale, with values of 0 (no), 1 (minimally), 2 (sometimes), 3 (quite a lot) and 4 (always).

After 7 days and coinciding with suture removal, participants were given a new 3item questionnaire, taken from Saunders et al. [6], in which they were asked: 1.- If you were to have the same procedure, now that you are aware of the existence of this product, would you request it? 2.- Did you feel an increase in your overall satisfaction after the procedure due to the reduction in the anaesthetic effect time? 3.- Would you recommend the use of this product to family and friends? The answers were No / Yes / Don't know or no response.

\subsection{Statistical analysis}

The data collected was entered in an Excel spreadsheet (MS Excel 2007, Microsoft Inc., Redmond, WA, USA). An independent statistician analysed the data with statistical 
software (SPSS Statistics, version 25.0, IBM Corp. Armonk. NY, USA). In the first phase, a descriptive study of frequencies was carried out, in which the mean, median, standard deviation and ranges were obtained. To compare the groups with quantitative variables, normality was first checked with the Shapiro-Wilk test statistic, and the Student's t-test or the non-parametric Mann-Whitney U-test was performed when normality was rejected. The study of qualitative variables was carried out using Pearson's Chi-Square test. A significance level of $p \leq 0.05$ was set.

\section{Results}

A total of 60 patients were included in the present study, 30 belonging to the CG (control) and 30 to the EG (OraVerse ${ }^{\circledR}$ ). The gender distribution of the participants was 22 females $(36.7 \%)$ and 38 males $(63.3 \%)$, with a $\mathrm{F} / \mathrm{M}$ ratio: $1 / 1.7$ The mean age of all the patients who participated in the study was $54.78 \pm 11.34$ years.

The mean duration of the procedures in both groups was $25.13 \pm 7.04$ minutes, with $25.58 \pm 7.63$ minutes in the CG and $24.68 \pm 6.49$ minutes in the EG. There were no significant differences in latency time and procedure time between the two groups.

In the CG at baseline, mean SBP was $128.37 \pm 14.225$, mean DBP $78.50 \pm 7.826, \mathrm{HR}$ was $74.93 \pm 11.867$ and $\mathrm{SaO}_{2}$ was $99 \%$. In the EG, SBP was $121.40 \pm 11.325$, DBP was $78.27 \pm$ $7.395, \mathrm{HR}$ was $75.73 \pm 8.944$ and $\mathrm{SaO}_{2}$ was $98.99 \pm 0.254 \%$. Ten minutes after the end of the procedure the mean results obtained after the measurements in the CG were SBP $128.40 \pm$ 14.98, DBP $80.87 \pm 10.05$, HR $72.33 \pm 10.16$ and $\mathrm{SaO}_{2} 99.00 \%$, while the mean results in the CG were SBP $125.20 \pm 11.59$, DBP $79.47 \pm 8.11$, HR $74.47 \pm 8.67$ and $\mathrm{SaO}_{2} 98.99 \pm 0.25 \%$. There were no significant differences between the two groups when compared (Table 1).

Table 1. Differences of means and statistical significance $(p<0.05)$ in both groups between baseline and final values.

\begin{tabular}{|c|c|c|c|c|c|c|c|c|}
\hline \multicolumn{9}{|c|}{ Baseline Values } \\
\hline & SBP & $p$ & DBP & $p$ & HR & $p$ & $\mathrm{SaO}_{2}$ & $p$ \\
\hline CG & 128,37 & \multirow{2}{*}{$0,041^{*}$} & 78,50 & \multirow{2}{*}{0,905} & 74,93 & \multirow{2}{*}{0,754} & $99 \%$ & \multirow{2}{*}{0,155} \\
\hline EG & 121,40 & & 78,27 & & 75,73 & & $98,99 \%$ & \\
\hline \multicolumn{9}{|c|}{ Final Values } \\
\hline & SBP & $p$ & DBP & $p$ & HR & $p$ & $\mathrm{SaO}_{2}$ & $p$ \\
\hline CG & 128,40 & \multirow{2}{*}{0,341} & 80,87 & \multirow{2}{*}{0,550} & 72,33 & \multirow{2}{*}{0,373} & $99 \%$ & \multirow{2}{*}{0,155} \\
\hline EG & 125,20 & & 79,47 & & 74,47 & & $98,99 \%$ & \\
\hline
\end{tabular}

CG: control group; EG: experimental group; SBP: systolic blood pressure; DBP: diastolic blood pressure; HR: heart rate; $\mathrm{SaO}_{2}: \mathrm{O}_{2}$ saturation. ${ }^{*} p<0.05$

Baseline values only differed in SBP, which were higher in the CG $(p=0.041)$. When comparing baseline versus final results, significant differences were again found in SBP, which showed an increase in the final recording compared to baseline in the EG $(p=0.011)$. In the CG there was a decrease in HR at the final recording compared to baseline $(p=$ 0.020).

The duration of the anaesthetic effect at the labial level (Figure 1), was longer in the CG with a mean of $190.05 \pm 49.99$ minutes, compared to the EG which was $87.14 \pm 53.36$ minutes $(p<0.001)$. These differences were also observed in recovery of tongue sensation (Figure 2), with values of $180.21 \pm 61.63$ minutes for the $C G$, compared to $78.27 \pm 44.92$ minutes for the EG $(p<0.001)$. 


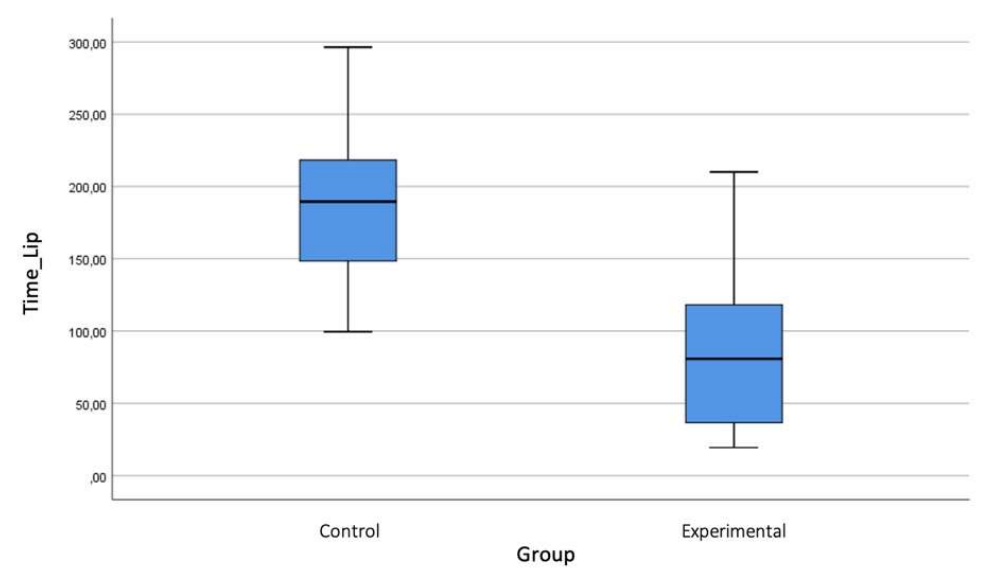

Figure 1. Blox-Plot showing the differences between the Control Group and the Experimental Group in recovery time for lip numbness.

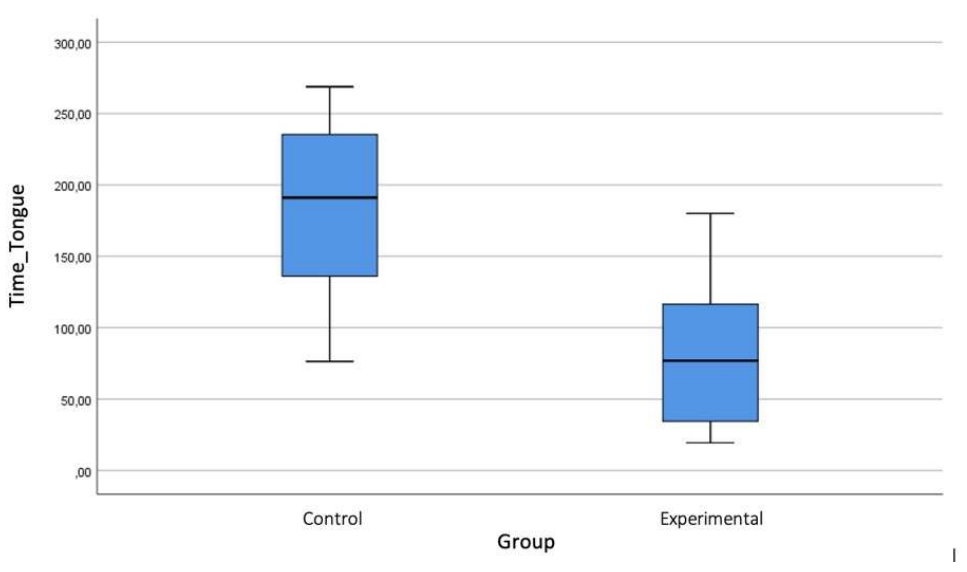

Figure 2. Blox-Plot showing the differences between the Control Group and the Experimental Group in recovery time for tongue numbness.

Postoperative pain intensity recorded by VAS (Figure 3) showed that, in both groups, the pain response was similar and of moderate intensity, with values between 0 and 5 . A similar situation occurred with the consumption of analgesics that were taken during the first 24 hours and absent in the subsequent controls.

Pain (VAS)

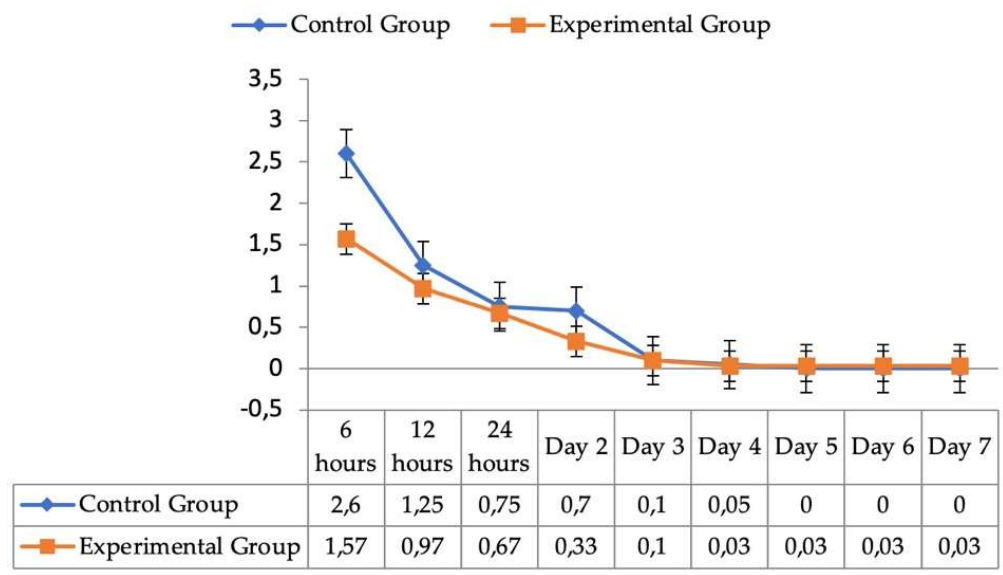

Figure 3. Mean values of pain intensity recorded by VAS. 
Analysis of the postoperative clinical questionnaire collected at 24 hours (Table 2) showed statistically significant differences in relation to difficulty in chewing $(p=0.01)$ and accidental bites $(p=0.05)$, which were greater in the CG. On the contrary, the EG recorded greater pain in the anaesthetic area $(p=0.043)$.

With regard to the possible adverse effects of OraVerse ${ }^{\circledR}$, no statistically significant values were obtained between the two groups. Speech impairment $(p=0.633)$, nausea $(p$ $=0.402)$; feeling of palpitation or dizziness $(p=0.31)$ and head or neck pain $(p=0.393)$, did not differ between the two groups.

Table 2. Clinical aspects and adverse effects collected during the first 24 hours postoperatively.

\begin{tabular}{|c|c|c|c|c|c|c|c|c|c|}
\hline \multicolumn{3}{|c|}{ Questions } & 0 & 1 & 2 & 3 & 4 & Average & $p$ \\
\hline \multirow{2}{*}{1} & Have you experienced speech & CG & $60 \%$ & $30 \%$ & $5 \%$ & $5 \%$ & & 0.55 & \multirow{2}{*}{0.253} \\
\hline & impairment? & EG & $76.7 \%$ & $13.3 \%$ & $10 \%$ & & & 0.33 & \\
\hline \multirow{2}{*}{2} & Have you had any difficulty & CG & $20 \%$ & $60 \%$ & $10 \%$ & $10 \%$ & & 1.10 & \multirow{2}{*}{$0.01 *$} \\
\hline & eating? & EG & $73.3 \%$ & $13.3 \%$ & $13.3 \%$ & & & 0.40 & \\
\hline \multirow{2}{*}{3} & Have you bitten your tongue, lip & CG & $80 \%$ & $5 \%$ & $15 \%$ & & & 0.35 & \multirow{2}{*}{$0.05^{*}$} \\
\hline & or cheek during this time? & EG & $96.7 \%$ & $3.3 \%$ & & & & 0.03 & \\
\hline \multirow{2}{*}{4} & Have you experienced more & CG & $75 \%$ & $10 \%$ & $10 \%$ & $5 \%$ & & 0.45 & \multirow{2}{*}{0.703} \\
\hline & salivation than usual? & EG & $66.7 \%$ & $26.7 \%$ & $3.3 \%$ & $3.3 \%$ & & 0.43 & \\
\hline \multirow{2}{*}{5} & Have you felt unwell? (headache, & CG & $95 \%$ & & $5 \%$ & & & 0.10 & \multirow{2}{*}{0.361} \\
\hline & nausea ...) & EG & $86.7 \%$ & $10 \%$ & & & $3.3 \%$ & 0.23 & \\
\hline \multirow{2}{*}{6} & Have you had difficulty & CG & $80 \%$ & $20 \%$ & & & & 0.20 & \multirow{2}{*}{0.523} \\
\hline & communicating? & EG & $73.3 \%$ & $20 \%$ & $6.7 \%$ & & & 0.33 & \\
\hline \multirow{2}{*}{7} & Have you felt a temporary & CG & $55 \%$ & $40 \%$ & & $5 \%$ & & 0.60 & \multirow{2}{*}{0.084} \\
\hline & decrease in your quality of life? & EG & $80 \%$ & $13.3 \%$ & $3.3 \%$ & $3.3 \%$ & & 0.30 & \\
\hline \multirow{3}{*}{8} & Have you had pain in the area & CG & $70 \%$ & $30 \%$ & & & & 0.30 & \multirow{3}{*}{$0.043^{*}$} \\
\hline & where the anaesthetic solution & EG & $46.7 \%$ & $30 \%$ & $16.7 \%$ & $3.3 \%$ & $3.3 \%$ & 0.87 & \\
\hline & was injected? & & & & & & & & \\
\hline \multirow{2}{*}{9} & Have you noticed palpitations or & CG & $100 \%$ & & & & & 0.00 & \multirow{2}{*}{0.414} \\
\hline & a dizzy feeling? (heart rate) & EG & $96.7 \%$ & $3.3 \%$ & & & & 0.03 & \\
\hline \multirow{2}{*}{10} & Have you had a headache or neck & CG & $90 \%$ & $10 \%$ & & & & 0.10 & \multirow{2}{*}{0.725} \\
\hline & pain? (blood pressure) & EG & $86.7 \%$ & $13.3 \%$ & & & & 0.13 & \\
\hline \multirow[b]{2}{*}{11} & Have you had an itching, & CG & $75 \%$ & $25 \%$ & & & & 0.25 & \multirow[t]{2}{*}{0.191} \\
\hline & $\begin{array}{l}\text { tingling, or burning sensation in } \\
\text { the area around the injection site? }\end{array}$ & $\mathrm{EG}$ & $60 \%$ & $26 \%$ & $10 \%$ & $3.3 \%$ & & 0.57 & \\
\hline
\end{tabular}

CG: control group; EG: experimental group. ${ }^{*} p<0.05$

In a 3-item questionnaire asking about satisfaction with OraVerse ${ }^{\circledR}, 83.3 \%$ of patients would request it again for other dental procedures; $76.1 \%$ were satisfied with the reduction in numbness time, and $83.3 \%$ would recommend it to family and friends.

\section{Discussion}

PM quickly reverses the anaesthetic effect, thus avoiding lip and cheek bites, speech impairment and, ultimately, reduced quality of life for patients [11,12,22]. So far, studies have mainly been conducted on its use after conservative dentistry treatments, but not after surgery or dental implants. 
According to Hersh et al. [9], the occurrence of haemodynamic adverse effects that may occur due to the use of PM can affect up to one in ten patients, with a decrease or increase in heart rate and an increase in blood pressure.

Laviola et al. [10] observed in their study that the most frequently occurring adverse effect, both in patients injected with PM and in the control group injected with placebo in similar proportions, was tachycardia, which in most cases occurred 10 minutes after injection of either the PM solution or placebo. Therefore, they concluded that administering one or two injections of $0.4 \mathrm{mg}$ PM is well tolerated, with the same number of adverse effects in patients treated with PM or placebo. In contrast, in the present study, heart rate monitoring showed that between baseline and final measurements there was a slight decrease in both groups, although these results were not significant.

In relation to blood pressure, differences were only observed in SBP, which was increased in the EG at 10 minutes after PM injection. Despite these differences, the mean SBP was $125.20 \mathrm{~mm} \mathrm{Hg}$, which is lower than the mean SBP of $128.40 \mathrm{~mm} \mathrm{Hg}$ measured 10 minutes after the end of the procedure in the CG, and does not represent a risk for patients. These results would be in line with those found by Daubländer et al. [23], who, following a multicentre study, concluded that the use of PM in routine dental treatment is well tolerated, effective and safe. However, these data contrast with those obtained by Hersh et al. [9], who reported an increase of $20 \mathrm{~mm} \mathrm{Hg}$ in both SBP and DBP at GE, while HR decreased by 20 beats/minute. These results may be due to the fact that the study was conducted in a child population.

In the literature review, adverse effects such as pain in the area of the PM injection, trismus, biting of the lip, tongue or cheek are also observed in some patients [24,25]. Vinnakota et al. [26] state, following a systematic review and meta-analysis, that although no serious complications have been reported with the use of PM, mild or moderate adverse effects have been reported compared to the control group, with age being considered as a factor that may have a significant effect. The results of the questionnaire given to patients in the present study, assessing the presence of adverse effects in the EG and CG, show no differences with regard to the presence of disorders such as difficulty in speech, headache or neck pain, presence of nausea, vomiting or palpitations.

Most studies on the use of PM in dentistry are related to conservative dentistry and non-invasive periodontal treatments. In the study carried out by Froum et al. [27] on patients undergoing dental implant surgery, anaesthetic effect reversal was used to assess early lower alveolar nerve involvement by measuring the time to recovery of lip and tongue sensation in a group of 10 patients, the presence of bleeding at the site of surgery, as well as redness and swelling at the site of injection of the anaesthetic solution and PM. No bleeding was observed in any of the 10 patients and 6 of them showed redness and swelling at the injection site. The study by Michaud et al. [17] found a higher number of patients in the EG with pain at the injection site, but no statistically significant differences with the CG. These results coincide with those reported in this study, where, although no side effects of interest were found, the EG did present greater pain in the injection area. This can be explained by the reversal of the anaesthetic effect due to the blocking of adrenergic activity and the additional volume of solution administered [28].

Regarding the duration of the anaesthetic effect on the tongue and lip, the results of this study show a significant reduction in the speed of the loss of anaesthetic sensation, coinciding with the results reported in the literature $[7,14,16]$. The main difference lies in the recovery times, which were somewhat shorter for authors such as Hersh et al. [7], who reported an average of 70 minutes for lip recovery and 60 minutes for tongue. Fowler et al. [15] observed a lip sensation recovery time of 47 minutes, although this shorter time could be explained by the use of lidocaine by these authors, whereas our study used articaine, which lasted longer.

In a recent study published by Gago et al. [29], using three local anaesthetics: lidocaine, articaine and bupivacaine, associated with a vasonconstrictor, in a randomised double-blind clinical trial, it was found that lip and tongue sensation recovery time was slightly higher than that observed in our study; 88.5 minutes for the lip and 84.5 minutes 
for the tongue. As there was no control group, their results were extrapolated from the duration times described by the manufacturers and reported in the literature. In a new randomised controlled clinical trial conducted with bupivacaine, Michaud et al. [30] also conclude that the use of PM significantly reverses the duration of the anaesthetic effect.

As for the presence of postoperative pain, a common symptom in surgical procedures in the oral cavity, no significant differences were found between the EG and CG. Therefore, although most studies with PM are conducted in conservative and paediatric treatments, it could be used in surgical and implant treatments, as this reversal of the anaesthetic effect did not lead to an increase in postoperative pain or analgesic consumption, compared to the CG.

Regarding patients' satisfaction with the use of PM, the study by Saunders et al. [6] showed a positive assessment, where $79 \%$ of patients would opt for the use of PM in future treatments, $84 \%$ considered it a better dental experience and $83 \%$ would recommend it to their family and friends. In turn, these authors reported dentists' satisfaction, where 86 and $82 \%$, respectively, stated that PM met a need in patients in their clinics and that it fulfilled the expectations of the product. These results coincide with those of the present study, where patients also reported a high degree of satisfaction with the use of PM, although they are somewhat lower than the results of Gago et al. [29], where 98.9\% of patients reported that they would recommend PM.

\section{Conclusions}

The use of PM in the placement of dental implants does not pose a risk of adverse cardiovascular effects in patients, nor an increase in postoperative pain, but it does improve patient satisfaction. However, randomised studies with larger numbers of participants and systemic problems would be needed to confirm the safety of PM.

Author Contributions: Conceptualization, I.L.B. and J.M.M.G.; methodology, I.L.B. and J.M.M.G.; validation, I.L.B. and J.M.M.G.; formal analysis, C.V.M. and C.M.G.; investigation, C.V.M.; resources, C.V.M. and N.M.R.; data curation, C.V.M. and C.M.G.; writing-original draft preparation, C.V.M.; writing-review and editing, I.L.B. and C.M.G.; visualization, C.V.M. and N.M.R; supervision, I.L.B. and J.M.M.G. All authors have read and agreed to the published version of the manuscript.

Funding: This research received no external funding.

Institutional Review Board Statement: The study was conducted according to the guidelines of the Declaration of Helsinki and approved by the Ethics Committee of Hospital Clínico San Carlos, Madrid (18/011-O_EPASP).

Informed Consent Statement: Informed consent was obtained from all subjects involved in the study.

Data Availability Statement: The databases used and/or analyzed during the current study are available from the corresponding author upon reasonable request.

Conflicts of Interest: The authors declare no conflict of interest.

\section{References}

1. Yang, F.; Gao, Y.; Zhang, L.; Zheng, B.; Wang, L.; Sun, H.; Huang, D. Local anaesthesia for surgical extraction of mandibular third molars: a systematic review and network meta-analysis. Clin Oral Investig 2020, 24, 3781-3800, doi: 10.1007/s00784-02003490-3.

2. Camps-Font, O.; Figueiredo, R.; Sánchez-Torres, A.; Clé-Ovejero. A.; Coulthard, P.; Gay-Escoda, C.; Valmaseda-Castellón, E. Which is the most suitable local anaesthetic when inferior nerve blocks are used for impacted mandibular third molar extraction? A network meta-analysis. Int J Oral Maxillofac Surg 2020, 49, 1497-1507, doi: 10.1016/j.ijom.2020.04.016.

3. Al-Shayyab, M.H.; Baqain, Z.H. Factors predictive of the onset and duration of action of local anesthesia in mandibular thirdmolar surgery: a prospective study. Eur J Oral Sci 2018, 126, 110-117, doi: 10.1111/eos.12406.

4. Boonsiriseth, K.; Chaimanakarn, S.; Chewpreecha, P.; Nonpassopon, N.; Khanijou, M.; Ping, B.; Wongsirichat, N. 4\% lidocaine versus $4 \%$ articaine for inferior alveolar nerve block in impacted lower third molar surgery. J Dent Anesth Pain Med 2017, 17, 2935, doi: 10.17245/jdapm.2017.17.1.29. 
5. Nourbakhsh, N.; Shirani, F.; Babaei, M. Effect of phentolamine mesylate on duration of soft tissue local anesthesia in children. J Res Pharm Pract 2012, 1, 55-59, doi: 10.4103/2279-042X.108371.

6. Saunders, T.R.; Psaltis, G.; Weston, J.F.; Yanase, R.R.; Rogy, S.S.; Ghalie, R.G. In-practice evaluation of OraVerse for the reversal of soft-tissue anesthesia after dental procedures. Compend Contin Educ Dent 2011, 32, 58-62.

7. Hersh, E.V.; Moore, P.A.; Papas, A.S.; Goodson, J.M.; Navalta, L.A.; Rogy, S.; Rutherford, B.; Yagiela, J.A. Reversal of soft-tissue local anesthesia with phentolamine mesylate in adolescents and adults. J Am Dent Assoc 2008, 139, 1080-1093. doi: 10.14219/jada.archive.2008.0311.

8. Rutherford, B.; Zeller, J.R.; Thake, D. Local and systemic toxicity of intraoral submucosal injections of phentolamine mesylate (OraVerse). Anesth Prog 2009, 56, 123-127, doi: 10.2344/0003-3006-56.4.123.

9. Hersh, E.V.; Lindemeyer, R.; Berg, J.H.; Casamassimo, P.S.; Chin, J.; Marberger, A.; Lin, B.P.; Hutcheson, M.C.; Moore, P.A. Phase four, randomized, double-blinded, controlled trial of phentolamine mesylate in two- to five-year-old dental patients. Pediatr Dent 2017, 39, 39-45.

10. Laviola, M.; McGavin, S.K.; Freer, G.A.; Plancich, G.; Woodbury, S.C.; Marinkovich, S.; Morrison, R.; Reader, A.; Rutherford, R.B.; Yagiela, J.A. Randomized study of phentolamine mesylate for reversal of local anesthesia. J Dent Res 2008, 87, 635-639, doi: $10.1177 / 154405910808700717$.

11. Morrow, T. OraVerse helps you lose that numbing feeling. Manag Care 2008, 17, 50-51.

12. Moore, P.A.; Hersh, E.V.; Papas, A.S.; Goodson, J.M.; Yagiela, J.A.; Rutherford, B.; Rogy, S.; Navalta, L. Pharmacokinetics of lidocaine with epinephrine following local anesthesia reversal with phentolamine mesylate. Anesth Prog 2008, 55, 40-48, doi: 10.2344/0003-3006(2008)55[40:POLWEF]2.0.CO;2.

13. Haghighat, A.; Davoudi, A.; Minaiyan, M.; Molai, M.; Afshar, A.; Basiri, K. Effect of a trial pharmaceutical solution on reversing sensations after using lidocain: An animal study. Anesth Essays Res 2015, 9, 79-82, doi: 10.4103/0259-1162.150182.

14. Prados-Frutos, J.C.; Rojo, R.; Gonzalez-Serrano, J.; Gonzalez-Serrano, C.; Sammartino, G.; Martinez-Gonzalez, J.M.; SánchezMoncescillo, A. Phentolamine mesylate to reverse oral soft-tissue local anesthesia: A systematic review and meta-analysis. $\mathrm{J} A m$ Dent Assoc 2015, 146, 751-759, doi: 10.1016/j.adaj.2015.04.018.

15. Fowler, S.; Nusstein, J.; Drum, M.; Reader, A.; Beck, M. Reversal of soft-tissue anesthesia in asymptomatic endodontic patients: a preliminary, prospective, randomized, single-blind study. J Endod 2011, 37, 1353-1358, doi: 10.1016/j.joen.2011.06.019.

16. Elmore, S.; Nusstein, J.; Drum, M.; Reader, A.; Beck, M.; Fowler, S. Reversal of pulpal and soft tissue anesthesia by using phentolamine: a prospective randomized, single-blind study. J Endod 2013, 39, 429-434, doi: 10.1016/j.joen.2012.12.024.

17. Michaud, P.L.; Flood, B.; Brillant, M.S. Reversing the effects of $2 \%$ lidocaine: A randomized controlled clinical trial. J Dent 2018, 72, 76-79, doi: 10.1016/j.jdent.2018.03.009.

18. Wynn, R.L. Phentolamine mesylate - an old medical drug becomes a new dental drug. Gen Dent 2009, 57, $200-202$.

19. Grover, H.S.; Gupta, A.; Saksena, N.; Saini, N. Phentolamine mesylate: It's role as a reversal agent for unwarranted prolonged local analgesia. J Indian Soc Pedod Prev Dent 2015, 33, 265-268, doi: 10.4103/0970-4388.165646.

20. Yagiela, J.A. What's new with phentolamine mesylate: a reversal agent for local anaesthesia? SAAD Dig 2011, $27,3-7$.

21. Tavares, M.; Goodson, J.M.; Studen-Pavlovich, D.; Yagiela, J.A.; Navalta, L.A.; Rogy, S.; Rutherford, B.; Gordon, S.; Papas, A.S. Reversal of soft-tissue local anesthesia with phentolamine mesylate in pediatric patients. J Am Dent Assoc 2008, 139, 1095-1104, doi: 10.14219/jada.archive.2008.0312.

22. Helmi, M.; AlDosari, M.; Tavares, M. Phentolamine Mesylate may be a safe and effective option to reduce discomfort and time to recovery after dental care with local anesthesia. J Evid Based Dent Pract 2018, 18, 181-184, doi: 10.1016/j.jebdp.2018.02.005.

23. Daubländer, M.; Liebaug, F.; Niedeggen, G.; Theobald, K.; Kürzinger, M.L. Effectiveness and safety of phentolamine mesylate in routine dental care. J Am Dent Assoc 2017, 148, 149-156, doi: 10.1016/j.adaj.2016.11.017.

24. Boynes, S.G.; Riley, A.E.; Milbee, S.; Bastin, M.R.; Price, M.E.; Ladson, A. Evaluating complications of local anesthesia administration and reversal with phentolamine mesylate in a portable pediatric dental clinic. Gen Dent 2013, 61, $70-76$.

25. Prasanna, J.S. OraVerse: reverses numbness after dental procedures. J Maxillofac Oral Surg 2012, 11, 212-219, doi: 10.1007/s12663011-0318-6.

26. Vinnakota, D.N.; Kamatham, R. Safety profile of phentolamine mesylate as reversal agent of pulpal and soft tissue dental anesthesia: a systematic review and meta-analysis. Quintessence Int 2019, 50, 568-575. doi: 10.3290/j.qi.a42574.

27. Froum, S.J.; Froum, S.H.; Malamed, S.F. The use of phentolamine mesylate to evaluate mandibular nerve damage following implant placement. Compend Contin Educ Dent 2010, 31, 520, 522-528.

28. Hersh, E.V.; Lindemeyer, R.G. Phentolamine mesylate for accelerating recovery from lip and tongue anesthesia. Dent Clin North Am 2010, 54, 631-642, doi: 10.1016/j.cden.2010.06.004.

29. Gago-García, A.; Barrilero-Martin, C.; Alobera-Gracia, M.A.; Del Canto-Pingarrón, M.; Seco-Calvo, J. Efficacy of phentolamine mesylate in reducing the duration of various local anesthetics. J Dent Anesth Pain Med 2021, 21, 49-59, doi: 10.17245/jdapm.2021.21.1.49.

30. Michaud, P.L.; Nowe, E.; Smith Brillant, M. Reversing the effects of $0.5 \%$ bupivacaine using phentolamine mesylate: A preliminary randomized controlled clinical trial. J Clin Pharmacol 2020, online ahead of print Jan 28, doi: 10.1002/jcph.1567. 